\title{
Synthesis of Metal and Ceramic Magnetic Nanoparticles by Levitational Gas Condensation (LGC)
}

\author{
Y. R. Uhm*, H. M. Lee, G. J. Lee, and C. K. Rhee \\ Nuclear Materials Research Division, Korea Atomic Energy Research Institute, Daejeon 305-353, Korea
}

(Received 15 January 2009, Received in final form 2 April 2009, Accepted 2 April 2009)

\begin{abstract}
Nickel (Ni) and ferrite $\left(\mathrm{Fe}_{3} \mathrm{O}_{4}, \mathrm{NiFe}_{2} \mathrm{O}_{4}\right)$ nanoparticles were synthesized by LGC using both wire feeding (WF) and micron powder feeding (MPF) systems. Phase evolution and magnetic properties were then investigated. The Ni nanopowder included magnetic-ordered phases. The LGC synthesis yielded spherical particles with large coercivity while the abnormal initial magnetization curve for $\mathrm{Ni}$ indicated a non-collinear magnetic structure between the core and surface layer of the particles. Since the XRD pattern cannot actually distinguish between magnetite $\left(\mathrm{Fe}_{3} \mathrm{O}_{4}\right)$ and maghemite $\left(\gamma-\mathrm{Fe}_{2} \mathrm{O}_{3}\right)$ as they have a spinel type structure, the phase of the iron oxide in the samples was unveiled by Mössbauer spectroscopy. The synthesized Ni-ferrite consisted of single domain particles, including an unusual ionic state. The synthesized nanopowder bore an active surface due to the defects that affected abnormal magnetic properties.
\end{abstract}

Keywords : nanopowder, levitational gas condensation (LGC)

\section{Introduction}

The development of new methods for nanopowder synthesis such as magnetron sputtering, melt spinning, and mechanical alloying, opens up new possibilities for nonequilibrium phases and nanocrystalline materials with new and unusual physical properties applicable to p-type semiconductors, catalysts, and drug delivery systems [12]. Among the various established preparation methods for nanopowders, mechanical alloying, micro-emulsion, sol-gel, and hydrothermal processes [3-5], simplicity, cost effectiveness, and environmental soundness are key. The levitational gas condensation (LGC) method is just such an approach [6]. In previous studies, the complicated levitation and evaporation mechanism for fabrication were explained thoroughly [6]. It has also been reported that a nanopowder synthesized by gas phase methods showed unusual magnetic properties due to a surface effects [7, 8]. However, it is impossible to synthesize several complicated metal doping materials such as ferrites, perovskite, garnet, metal-doped $\mathrm{ZnO}$, Ti-Ni, and $\mathrm{Al}-\mathrm{Ni}-\mathrm{Co}$, because the supply of the parent materials into the levitated drop in the induction coil was a wire feeding system. Never-

*Corresponding author: Tel: +82-42-868-4835

Fax: +82-42-868-4847, e-mail: uyrang@kaeri.re.kr theless, the newly modified micron powder feeding system (MPF) overcame this doping problem of the LGC system [9].

In this study, several magnetic particles were synthesized by a simple, one-step levitational gas condensation (LGC) method using an MPF system, and the magnetic properties, including ionic states of the iron, were investigated by Mössbauer spectroscopy.

\section{Experimental Technique}

\subsection{Synthesis of Magnetic Metal Nanoparticles (Ni)}

A schematic illustration of the equipment for preparing the nanoparticles via LGC is shown in Ref. [6]. A suspended melt drop blown by inert gas (Ar) is heated to $2000^{\circ} \mathrm{C}$ by a high-frequency induction generator. The metallic atoms, evaporated from the overheated surface, were condensed by a cold inert gas and collected from the filter. To stabilize the powder surface, the powders were passivated with thin oxide layers. The apparatus consisted of a high-frequency induction generator of $6 \mathrm{~kW}$, a levitation and evaporation chamber, and an oxygen concentration control unit. The wire feeding velocities for nickel $\left(V_{\mathrm{Ni}}\right)$ were $50 \mathrm{~mm} / \mathrm{min}$. The Ar pressure in the chamber was $18 \mathrm{kPa}$. 


\subsection{Synthesis of Ferrite Nanoparticles $\left(\mathrm{Fe}_{3} \mathrm{O}_{4}, \mathrm{NiFe}_{2} \mathrm{O}_{4}\right)$}

High purity $\mathrm{Fe}_{2} \mathrm{O}_{3}$ powders were synthesized by a LGC method. The apparatus consisted of a high frequency induction generator of $5 \mathrm{~kW}$, a levitation and evaporation chamber, and an oxygen concentration control unit. The wire feeding velocity $\left(V_{\mathrm{Fe}}\right)$ and mixed $\mathrm{Ar}$ and $\mathrm{O}_{2}$ gas pressures in the chamber was $50 \mathrm{~mm} / \mathrm{min}$ and $18 \mathrm{kPa}$, respectively.

The $\mathrm{NiFe}_{2} \mathrm{O}_{4}$ powders were synthesized by the LGC method using a micron powder feeding (MPF) system [9]. The apparatus consisted of a high-frequency induction generator of $6 \mathrm{~kW}$. The starting materials were mixed micron powders of $\mathrm{Ni}$ and $\mathrm{Fe}$ at a size range of 100 to $500 \mu \mathrm{m}$. The amount of micron powder fed into the liquid droplet of the seed was controlled at $80 \mathrm{mg} / \mathrm{min}$. The mixed $\mathrm{Ar}$ and $\mathrm{O}_{2}$ gas pressures in the chamber were 18 $\mathrm{kPa}$.

\subsection{Characterization of Magnetic Nanoparticles}

The as-prepared samples were characterized by XRD, vibrating sample magnetometry (VSM), and Mössbauer spectroscopy. Magnetization data were taken using a magnetometer, Lake Shore. Inc (Westerville, Ohio, USA). A Mössbauer spectrometer of the electromechanical type was used in the constant-acceleration mode [10].

\section{Results and Discussion}

\subsection{Magnetic Metal Nanoparticles (Ni, Fe)}

The nanocrystalline Ni synthesized by LGC using the wire feeding system was confirmed by its XRD pattern, Fig. 1. The XRD results show the lattice parameters and position of the main peaks of the Ni powders. A small amount of the $\mathrm{NiO}$ phase was found in the XRD patterns and the TEM images, resulting from a passivated layer on the powder surface.

The microstructure and phase composition of the $\mathrm{Ni}$ powders were studied with transmission electron microscopy (TEM). The particle consisted of a single domain. Powders with single domains were synthesized by a special gas phase method, though the average particle size was over $100 \mathrm{~nm}[7,8]$. Thin oxide layers on the powders formed a continuous coating at a thickness of 2.0-3.0 nm. Nanocrystalline Ni particles synthesized using the wire feeding (WF) system showed a spherical shape, Fig. 2. The TEM image showed that nanocrystalline Ni powders consisted of particles ranging from 15 to $40 \mathrm{~nm}$.

The magnetic properties of the nanopowders were affected by the size effect resulting from the anisotropy field and magnetic domain effect on the particles [11]. The powders synthesized by LGC, showing low saturation

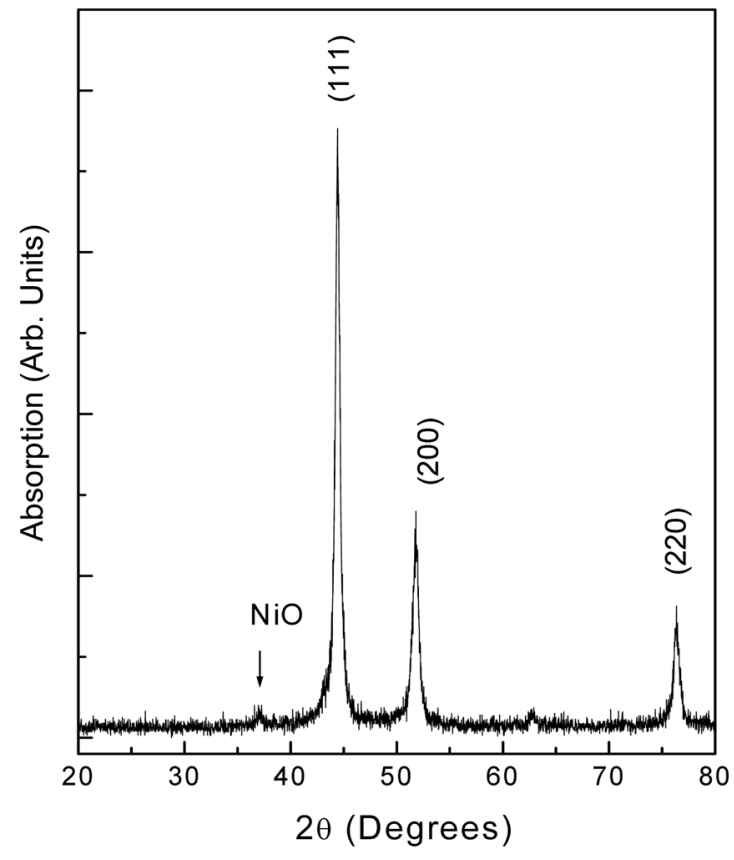

Fig. 1. X-ray diffraction (XRD) patterns using $\mathrm{Cu}-\mathrm{K} \alpha$ for the Ni synthesized by LGC.

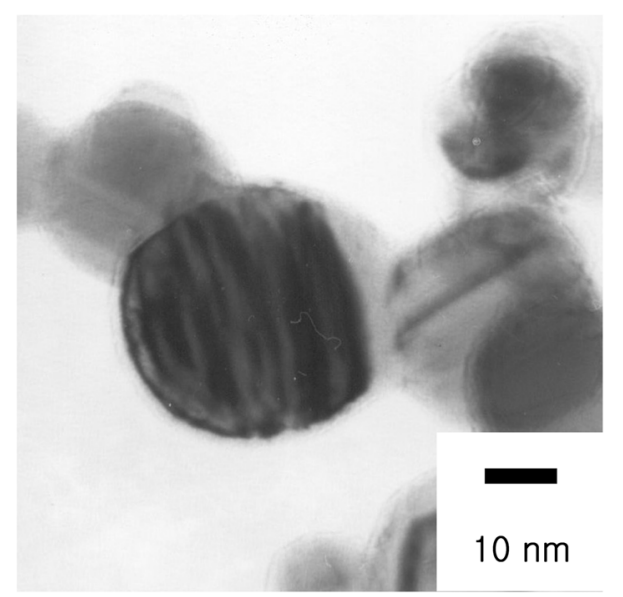

Fig. 2. TEM observation results show Ni synthesized using WF.

magnetization for the $\mathrm{Ni}$, were probably due to the spincoating effect and oxide phase on the surface [12]. The saturation magnetization was $M_{\mathrm{S}}=42 \mathrm{emu} / \mathrm{g}$. In Fig. 3, the hysteresis loop of the $\mathrm{Ni}$ in the low fields is shown. The slightly shifted hysteresis loop for the Ni sample can be explained by an exchange bias between the ferromagnetic core of the $\mathrm{Ni}$ and the antiferromagnetic surface of the $\mathrm{NiO}$ [9]; the hysteresis loop of the $\mathrm{Ni}$ in the low fields is shown. The symbol of the arrow indicates that the magnetization curve is placed out of the range of the hysteresis loop. The initial magnetization curve is not explained by size effect. More detailed analysis of the 

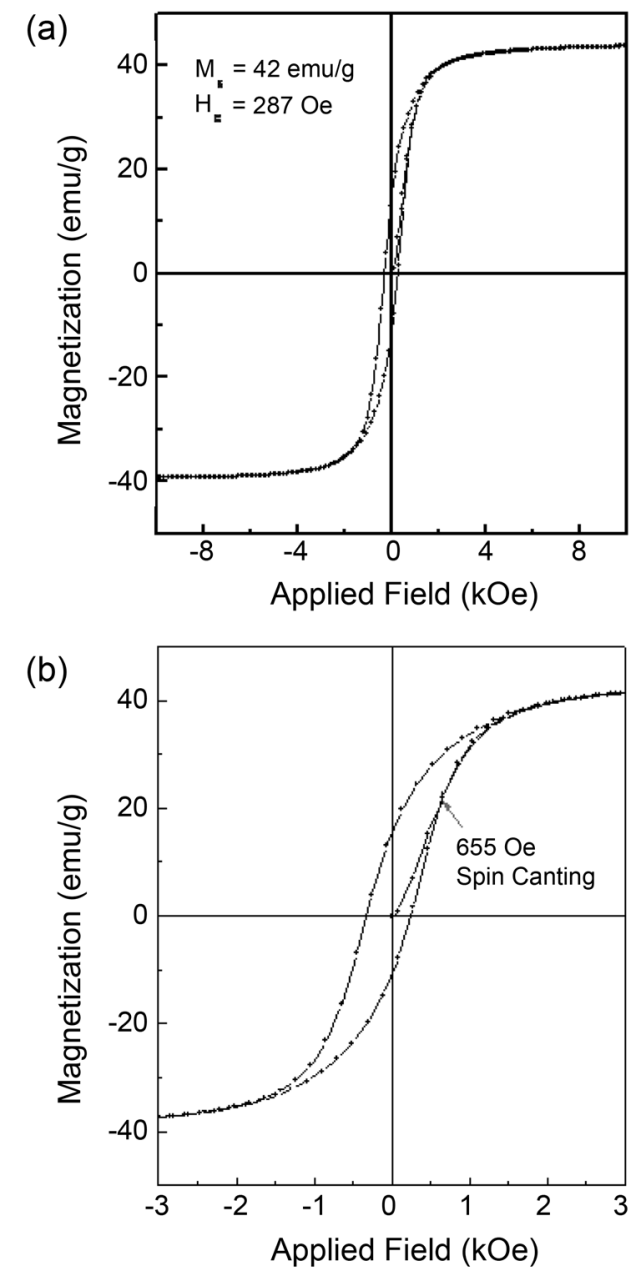

Fig. 3. Hysteresis loops for $\mathrm{Ni}$ (a) within an applied field of 10 $\mathrm{kOe}$ and (b) within an applied field of $3 \mathrm{kOe}$.

hysteresis properties of the Ni sample confirmed the noncollinear magnetic structure. The virgin magnetization curve slightly spilt over the limited hysteresis loop at 655 Oe, Fig. 3(b). It is assumed that this effect is enhanced when particle size reduced, which also increases the defects and the different magnetic structures on the surface of the particles [11]. The nature of this irreversibility in high magnetic fields allows for the description of a physical model $[11,12]$. This irreversibility can be explained by spin-glass or spin-canting behavior.

\subsection{Ferrite Nanoparticles $\left(\mathrm{Fe}_{3} \mathrm{O}_{4}\right.$ and $\left.\mathrm{NiFe}_{2} \mathrm{O}_{4}\right)$}

A liquid droplet, levitated by the magnetic force acting against the gravitational force due to the coupled induction coils, is heated to $2000^{\circ} \mathrm{C}$, causing the metallic atoms to evaporate from the overheated liquid droplet surface, condense by a cold inert gas, and collect into a filter. At the same time, the molecular $\mathrm{O}_{2}$ introduced into the chamber is converted to atomic $\mathrm{O}$ with high activity under high

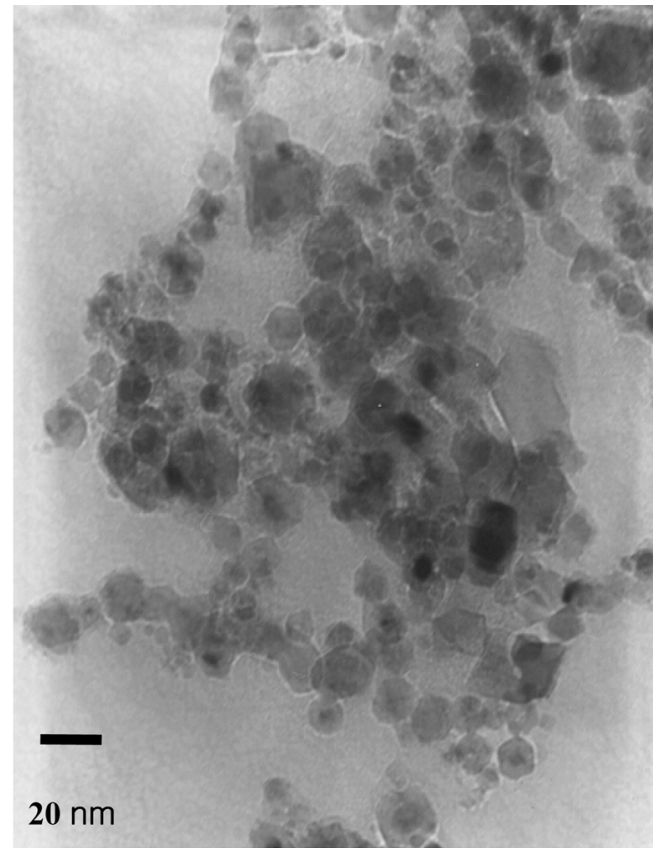

Fig. 4. TEM observation results showing the $\mathrm{Fe}_{3} \mathrm{O}_{4}$ under an $\mathrm{O}_{2}$ flow rate of $0.15 \leq V_{\mathrm{O}_{2}}(\mathrm{~L} / \mathrm{min}) \leq 0.2$, synthesized by LGC.

temperature. The highly active $\mathrm{O}$ atoms can then diffuse into Fe clusters and react with the Fe atoms [6]. The $\alpha$-Fe phase was observed at and below a $V_{\mathrm{O}_{2}}=0.05(\mathrm{~L} / \mathrm{min})$ oxygen flow rate. At and above a $0.2(\mathrm{~L} / \mathrm{min}) \mathrm{O}_{2}$ flow rate, levitation was not possible. The $\gamma-\mathrm{Fe}_{2} \mathrm{O}_{3}$ and $\alpha$-Fe phase were observed at and below a $V_{\mathrm{O}_{2}}=0.15(\mathrm{~L} / \mathrm{min})$ oxygen flow rate. At and above 0.15 (L/min), nanocrystalline $\mathrm{Fe}_{3} \mathrm{O}_{4}$ phases were synthesized. Fig. 4 shows the TEM images, indicating that the nanocrystalline $\mathrm{Fe}_{3} \mathrm{O}_{4}$ powders were spherical with sizes ranging from 14 to 30 nm.

Since the XRD pattern cannot actually distinguish between magnetite $\left(\mathrm{Fe}_{3} \mathrm{O}_{4}\right)$ and maghemite $\left(\gamma-\mathrm{Fe}_{2} \mathrm{O}_{3}\right)$, given their spinel-type structures, the phase of iron oxide in the samples was unveiled by the Mössbauer spectrum as shown in Fig. 5. The structure of the magnetite $\left(\mathrm{Fe}_{3} \mathrm{O}_{4}\right)$ consisted of 2 sub-structures of the octahedral $\left(O_{\mathrm{h}}\right)$ and tetrahedral $\left(T_{\mathrm{d}}\right)$ sites, including $\mathrm{Fe}^{2+}$ and $\mathrm{Fe}^{3+}$, respectively [13]. The isomer shifts and the magnetic hyperfine interaction field of the Mössbauer spectrum and information on the valence state of iron. The Mössbauer spectrum at room temperature in Fig. 5(a) consisted of 2 sets of sextet Lorentzian lines. Two superimposed sextets corresponded to $\alpha$-Fe and $\mathrm{Fe}^{3+}$ of the $\gamma-\mathrm{Fe}_{2} \mathrm{O}_{3}$, respectively [14]. The parameters of the Mössbauer spectrum were consistent with the hyperfine values reported for $\gamma-\mathrm{Fe}_{2} \mathrm{O}_{3}$ by R. M. Cornell et al. [15] A detailed analysis yielded that the respective amounts of $\alpha-\mathrm{Fe}$ and $\gamma-\mathrm{Fe}_{2} \mathrm{O}_{3}$ were 7 


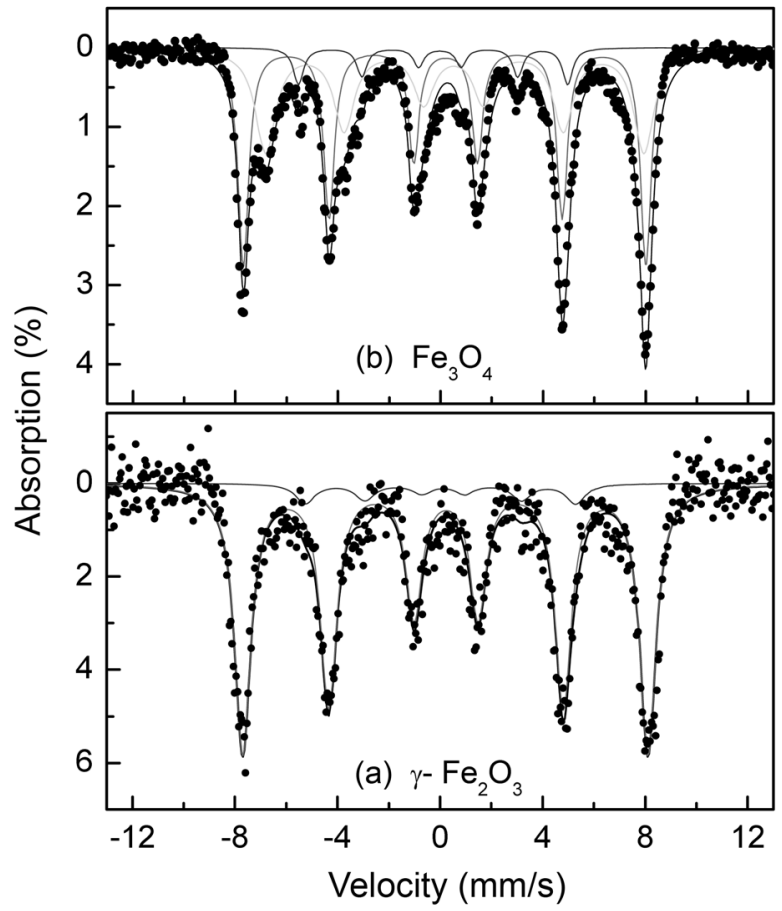

Fig. 5. Mössbauer spectra for (a) $\gamma-\mathrm{Fe}_{2} \mathrm{O}_{3}$ and $\alpha$-Fe, and (b) $\mathrm{Fe}_{3} \mathrm{O}_{4}$ and $\alpha$-Fe.

and 93\%, respectively. The Mössbauer spectrum indicated magnetic hyperfine fields due to particle sizes of 14 to 30 nm [13]. The Mössbauer spectrum at room temperature in Fig. 5(b) consists of 3 sets of sextet Lorentzian lines. Three superimposed sextets corresponded to $\alpha-\mathrm{Fe}, \mathrm{Fe}^{2+}$, and $\mathrm{Fe}^{3+}$ of $\mathrm{Fe}_{3} \mathrm{O}_{4}$, respectively [13]. The fraction of spectrum absorption indicated that most particles became magnetically ordered. A detailed analysis yielded respective amounts of $\alpha-\mathrm{Fe}$ and $\mathrm{Fe}_{3} \mathrm{O}_{4}$ at 8 and $92 \%$.

Characterization of the crystal structure of the powders was carried out by x-ray diffraction (XRD). The positions and relative intensities of all the main diffraction patterns and characteristic reflections, such as (220), (311), (222), (400), (422), (511), and (440), as well as the calculated lattice parameters, were in agreement with those in the standard XRD card (JCPDS10-325) of Ni-ferrite. The peak arising from (400), located near $2^{\circ}$ of $43^{\circ}$, was too large. This peak position was very close to the main peak of NiO. With the observation of each peak, it was clarified that a small amount of $\mathrm{NiO}$ was contained in the ferrite. The estimated amount of $\mathrm{NiO}$ was $7 \%$ by comparing with peak intensities, resulting from different vapour cooling temperatures between $\mathrm{Ni}$ and $\mathrm{Fe}$. The range of particle size was 8 to $22 \mathrm{~nm}$, comparable to the crystallite size calculated from the XRD. A specific surface area of $8.5 \mathrm{~m}^{2} / \mathrm{g}$ measured by BET contributed to an estimated average particle size of $13 \mathrm{~nm}$. In the lattice of the spinel

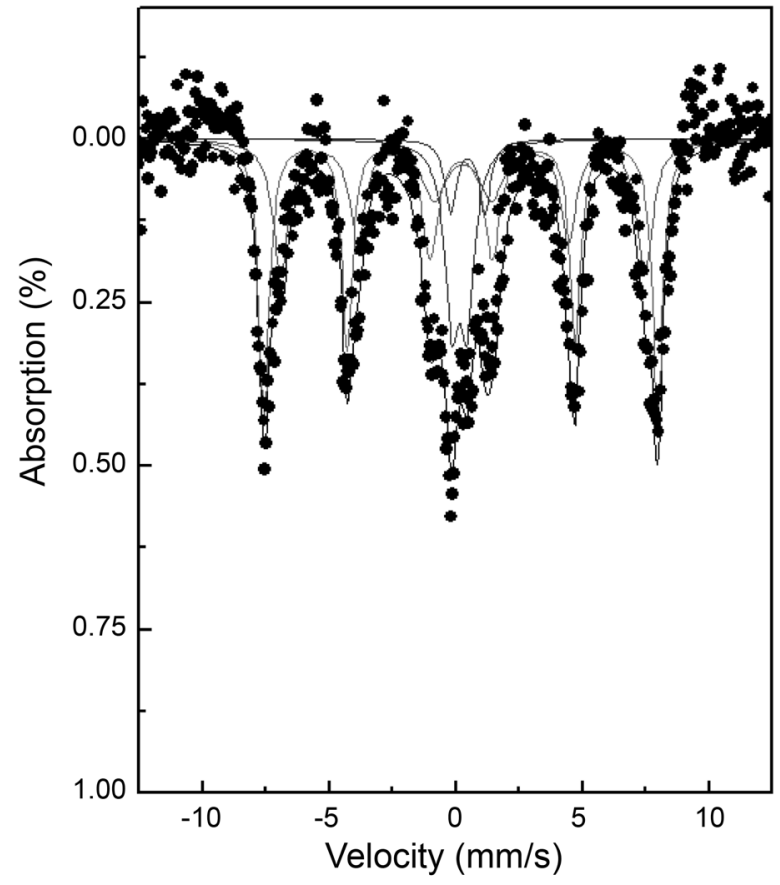

Fig. 6. Mössbauer spectrum for $\mathrm{NiFe}_{2} \mathrm{O}_{4}$ measured at $295 \mathrm{~K}$.

compound, there were 2 kinds of oxygen polyhedra, octahedron $\left(O_{\mathrm{h}}\right)$ and tetrahedron $\left(T_{\mathrm{d}}\right)$. In the lattice of the nickel ferrite, with a completely inverse spinel structure, there were an equal number of $\mathrm{Fe}^{3+}$ ions at the $T_{\mathrm{d}}$ and $O_{\mathrm{h}}$ sites, respectively [3]. However, as Fig. 6 shows, there were 2 sets of sextet Lorentzian and 2 sets of doublets in the Mössbauer spectrum for Ni-ferrite. The 2 sets of sextets correspond to trivalent iron ranging from 12 to $25 \mathrm{~nm}$ at the $T_{\mathrm{d}}$ and the $O_{\mathrm{h}}$ sites. One doublet corresponds to a trivalent iron ranging at and below $12 \mathrm{~nm}$, while the other indicates the existence of the $\mathrm{Fe}^{2+}$ ion ranging at and below $12 \mathrm{~nm}$ at the $O_{\mathrm{h}}$ site. A detailed analysis yielded 9 and $7 \%$ for the $\mathrm{Fe}^{3+}$ and $\mathrm{Fe}^{2+}$ at the octahedral site, respectively. The isomer shift of $0.54(\mathrm{~mm} / \mathrm{s})$ in the second doublet indicates that the sample contains $\mathrm{Fe}^{2+}$ in the ionic state. The presence of $\mathrm{Fe}^{2+}$ is predominantly due to the hopping of electrons from $\mathrm{Fe}^{3+}$ to $\mathrm{Fe}^{2+}$, as follows:

$$
\mathrm{Fe}^{3+} \Leftrightarrow \mathrm{Fe}^{2+}, \mathrm{Fe}^{3+}
$$

From the results of the Mössbauer spectrum, Ni-ferrite synthesized by LGC includes an unusual ionic state [3]. The presence of $\mathrm{Fe}^{2+}$ is justified by cation vacancies in the ferrite lattice and the possibility of the presence of both $\mathrm{Ni}^{3+}$ ions and oxygen vacancies could be considered for the charge compensation in the ferrite. It is looked forwarded that the as prepared sample shows the high catalytic effect due to the oxygen vacancy on the surface layer, when it is used as catalyst in the chemical reaction [16]. 


\section{Conclusions}

Nanocrystalline $\mathrm{Ni}$ and ferrite $\left(\mathrm{Fe}_{3} \mathrm{O}_{4}\right.$ and $\left.\mathrm{NiFe}_{2} \mathrm{O}_{4}\right)$ were synthesized by a levitational gas condensation (LGC) method using wire feeding (WF) and micron powder feeding (MPF) systems. The magnetic properties were characterized using vibrating sample magnetometry (VSM) and Mössbauer spectroscopy. The Mössbauer spectra revealed the presence of a superparamagnetic phase with ionic states of $\mathrm{Fe}^{2+}$ and $\mathrm{Fe}^{3+}$, such that the spinel-type structures of $\mathrm{Fe}_{3} \mathrm{O}_{4}$ and $\gamma-\mathrm{Fe}_{2} \mathrm{O}_{3}$ could be distinguished by Mössbauer spectroscopy. The size and shape of the nanopowders were investigated by transmission microscopy (TEM). The surface effect might influence the magnetic hysteresis behavior of the nanopowders. In the case of Ni-ferrite, it consisted of single domain particles that included an unusual ionic state. The presented, simple and environmental friendly synthesis using metal powders as parent materials can be extended to prepare other nanoparticles with scientifically interesting properties.

\section{Acknowledgment}

This work was supported by Cooperation Research Project funded by Ministry of Education, Science and Technology, Republic of Korea.

\section{References}

[1] H. Morrish and K. Haneda, J. Appl. Phys. 52, 2496 (1981).

[2] J. Fang, N. Shama, L. D. Tung, E. Y. Shin, and A. J.
O’Connor, J. Appl. Phys. 93, 7483 (2003).

[3] Y. Kinemuchi, K. Ishizaka, H. Suematsu, W. Jiang, and K. Yasui, Thin Solid Film 407, 109 (2002).

[4] K. V. P. M. Shafi, Y. Koltypin, and A. Gedanken, J. Phys. Chem. B 101, 6409 (1997).

[5] Y. Shi, J. Ding, and X. Liu, J. Magn. Magm. Mater. 205, 249 (1999).

[6] Y. R. Uhm, W. W. Kim, and C. K. Rhee, Phys. Stat. Sol. A 201, 1934 (2004).

[7] Y. R. Uhm, J. H. Park, W. W. Kim, C.-H. Cho, and C. K. Rhee, Mater, Sci. Eng. B 106, 224 (2004).

[8] Y. R. Uhm, W. W. Kim, C. K. Rhee, S. J. Kim, and C. S. Kim, J. Appl. Phys. 93, 7196 (2003).

[9] Y. R. Uhm, B. S. Han, M. K. Lee, S. J. Hong, and C. K. Rhee, Mater, Sci. Eng. A 449-451, 813 (2007).

[10] Y. R. Uhm and C. S. Kim, J. Appl. Phys. 89, 7344 (2001).

[11] B. D. Cullity, Introduction to Magnetic Materials (Addison-Wesley, Reading, MA, 1972).

[12] A. Ye, Yermakov, M. A. Uimin, A. A. Mysik, A. Yu, korobeinikov, A. V. Korolyov, N. V. Mushnikov, T. Goto, V. S. Gavoko, and N. N. Schegoleva, Mater. Sci. Forum, 386-388, 455 (2002).

[13] X. N. Xu, Y. Wolfus, A. Shaulov, Y. Yeshurun, I. Felner, I. Nowik, Yu. Koltypin, and A. Gedanken, J. Appl. Phys. 91, 4611 (2002).

[14] A. A. Novakova, V. Yu. Lanchinskaya, A. V. Volkov, T. S. Gendler, T. Yu. Kiseleva, M. A. Moskvina, and S. B. Zezin, J. Magn. Magn. Mater. 258-259, 354 (2003).

[15] R. M. Cornell and U. Schwertmann, The Iron Oxides, (Wiley-VCH, Weinheim, 1996).

[16] H. Falcón, R. E. Carbonio, and J. L. G. Fierro, J. Catal. 203, 264 (2001). 